\title{
Identification of students' misconceptions in proving onto and one-to- one function in abstract algebra using certainty response index
}

\author{
Muhammad Islahul Mukmin ${ }^{1}$, Arini Mayan Fa'ani ${ }^{2 *}$ \\ ${ }^{1,2}$ Universitas Islam Negeri Maulana Malik Ibrahim Malang, Jalan Gajayana No.50 Malang, Indonesia
}

\begin{tabular}{ll}
\hline A R T I C L E I N F O & A B S T R A C T \\
Original Article & This research is aimed to identify students misconceptions in \\
doi: 10.18860/ijtlm.v2i1.8582 & proving onto and one-to-one function in Abstract Algebra using \\
\hline Keywords: & CRI (Certainty Response Index), which is an instrument to \\
Misconceptions, Errors, CRI & distinguish misconceptions and errors. This research uses \\
& qualitative method. There are eighteen research participants, and \\
& they are Mathematics Education students in 3rd semester. \\
& Researchers asked participants to solve some problems related to \\
& mathematical proof. Then, participants gave score based on their \\
& belief or level of certainty. The result shows that ten students get \\
& misconceptions. They were weak in understanding the definition of \\
& onto and one-to-one function, and are not yet trained to proof onto \\
& and one-to-one function in Abstract Algebra. Further, this research \\
& also find that the errors of participants in proving mathematics are \\
mainly influenced by errors in algebraic operation.
\end{tabular}

(C) 2019 IJTLM. All rights reserved.

\footnotetext{
*Corresponding author.

E-mail: iniarinimayan@uin-malang.ac.id
}

How to cite: Mukmin, M. I., \& Fa'ani, A. M. (2019). Identification of students' misconceptions in proving onto and one-to-one function in abstract algebra using certainty response index. International Journal on Teaching and Learning Mathematics, 2(1), 1-6.

\section{INTRODUCTION}

The 21st century encourages us to have the ability to think critically, creatively, collaborate and communicate (Griffin, McGaw, \& Care, 2012). This skill is trained through learning Mathematics. In the college curriculum, there is a course specifically designed to practice critical thinking skills. One of them is Abstract Algebra. The ability to think critically can be seen in their proofing ability in identifying several onto and one-to-one functions, or justify several theorems related to functions. Study of mathematical proof could develop the students' ability to think critically in other domains of explanation (Dawkins \& Weber, 2017; Lesseig, 2016; Mata-Pereira \& da Ponte, 2017; Reid, 2005). Seeing students' misconceptions in proving functions is one technique to see ability to think critically. Therefore, analyzing students' misconception is very important study.

The systematic error is experienced by students in a relatively long time. This systematic error is an error that occurs in students on aspects of student procedural knowledge, conceptual knowledge, or both. Some errors that often occur in students are calculation errors. While Radatz states mathematics as a language identifies errors experienced by students so far into students' mistakes in understanding mathematical concepts, symbols, and vocabulary (Li, 2016). There are three kinds of error, namely: structural errors, arbitrary errors, executive mistakes (Orton, 1983). Students' misconceptions are very strongly in cognitive structures. It influences 
in a fundamental sense how students understand natural phenomena and argumentation (Boero, Fenaroli, \& Guala, 2018; Hammer, 1996; Moon, Stanford, Cole, \& Towns, 2017).

Identification of misconceptions is a fertile area in education research, it should be distinguished from lack of knowledge. Misconception strongly held cognitive structures that are different from the accepted understanding in a field and it can interfere new knowledge's construction. While a lack of concept or knowledge can be remedied with instruction and subsequent learning (Hammer, 1996). It is important to distinguish a lack of knowledge from a misconception. Although both are the same in interfere students' new knowledge, but the instructional methods for eliminating misconceptions and for remedying a lack of knowledge can differ easily (Hasan, Bagayoko, \& Kelley, 1999).

One method that is usually used to distinguish students' errors and misconceptions is CRI (Certainty Response Index). It is an instrument used to measure the degree of certainty response (Hasan, et.al, 1999). Researchers asked participants to give a score based on their belief or level of certainty. Certainty is related to their belief in using well knowledge, concepts, or principles. CRI often uses a certain scale. For example, a six-point scale (0-5) where 0 means that students only guess in total or lack of knowledge for the procedures or laws of the questions, while a score of 5 indicates that students have very self-confidence in answering the questions. Likewise, when researcher asked students to give a score of CRI, it means that we instruct them to make their own judgements about the certainty of proving an onto and one-to-one function in Abstract Algebra. Table 1 shows the score and level of CRI (Certainty Response Index).

Table 1. Score and Level of Certainty

\begin{tabular}{|c|l|}
\hline Score & Level of Certainty \\
\hline 0 & Totally guessed answer \\
\hline 1 & Almost guess \\
\hline 2 & Not sure \\
\hline 3 & Sure \\
\hline 4 & Almost Certain \\
\hline 5 & Certain \\
\hline
\end{tabular}

Students with low level of CRI $(<2,5)$ shows that they donot understand about the subject, just guessing to answer the questions, and donot have a good conception about the subject or question. While students with high level of CRI $(>2,5)$ shows that they have a good confidence to answer the question or solve the problems. There are two possibilities in high level of CRI, confidence in correct answer shows that students has a good knowledge about the subject and confidence in wrong answer show that there are misconception. This is the way to distinguish between students' misconception and lack of knowledge. Table 2 shows the characteristics to distinguish misconception, lack of knowledge, lucky guess, and knowledge of correct concept.

Table 2. Decision matrix for students and given question, based on combination of correct or wrong answer and of low or high CRI

\begin{tabular}{|c|c|c|}
\hline & Low level of CRI $(<2,5)$ & \multicolumn{2}{|c|}{ High Level of CRI $(>2,5)$} \\
\hline Correct answer & $\begin{array}{c}\text { Correct answer and low CRI } \\
\text { (lucky guess) }\end{array}$ & $\begin{array}{c}\text { Correct answer and high CRI } \\
\text { (knowledge of correct concept) }\end{array}$ \\
\hline Wrong answer & $\begin{array}{c}\text { Wrong answer and low CRI (lack } \\
\text { of knowledge) }\end{array}$ & $\begin{array}{c}\text { Wrong answer and high CRI } \\
\text { (Misconception) }\end{array}$ \\
\hline
\end{tabular}




\section{METHOD}

The methode which used in this research is descriptive-qualitative. The descriptive research is aimed to describe phenomena that are little known or to identify a new phenomena (Dulock,1993). The qualitative research is aimed to understand the phenomena which contains behavior, perception, action (Creswell, 2012). We use supporting instruments likes algebra test, questionnaires, and interviews.

In this study, we identify some students misconseptions and errors in proving onto and oneto-one function in Abstract Algebra course offered to Mathematics Education students. They are eighteen research participants. To collect data, we use diagnostic test related to onto and one-toone function. The participants were requested to write the degree of certainty he has in his own ability to select and utilize well-established knowledge, concepts or laws to arrive at the answer of examination or test. The test contains two indicators. The first indicator is related to the ability of students to identify whether the sample functions presented in the problem are onto functions and injective functions. The second indicator is related to student skills in justifying a theorem on the inverse function.

\section{RESULTS AND DISCUSSION}

Students made variety reasons in mathematical proofs. Table 3 shows students' test results analyzed by using CRI.

Table 3. The number of students in knowledge of correct concept, lucky guess, lack of knowledge, and

\begin{tabular}{|l|c|c|c|c|}
\hline \multicolumn{1}{|c|}{ Question/Proving } & $\begin{array}{c}\text { Knowledge of } \\
\text { correct concept }\end{array}$ & Lucky guess & $\begin{array}{c}\text { Lack of } \\
\text { knowledge }\end{array}$ & Misconception \\
\hline Onto function & 1 & 0 & 9 & 8 \\
\hline One-to-one function & 9 & 1 & 4 & 4 \\
\hline
\end{tabular}

Based on analysis in Table 3, students tend to get misconception in proving onto function than one-to-one function. This is because in proving onto function, students should use counterexample while in proving one-to-one function students just proving with direct proof. This research found that some types of misconceptions; (1) proving a general case just by specific examples (misconception of representation); (2) misconceptions about mathematical symbols (misconceptions of symbols); (3) proving by misusing proving strategy (misconception of the proofs strategy). Next will be explained about the three types of misconceptions.

\subsection{Misconception of Representation}

A mapping or function from $A$ to $B$ is onto if and only if every element of $B$ is an image of at least one element in $A$. A standard way to demonstrate that $f: A \rightarrow B$ is onto is to take an arbitrary element $b$ in $B$ and show (usually by some kinds of formula or algebraic operation) that there exists an element $a$ in $A$ such that $b=f(a)$ (Gilbert \& Gilbert, 2009). But students who experienced misconception of representation take a fixed element in B and show that it has an inverse image in A to prove that a function is onto. It shows that they tend to use an example to prove a general case. Subjects ignore the condition that codomain should entirely has in inverse image in domain, so they just take an example to show a general case. Figure 1 is students' test result who experience misconceptions of representation. 


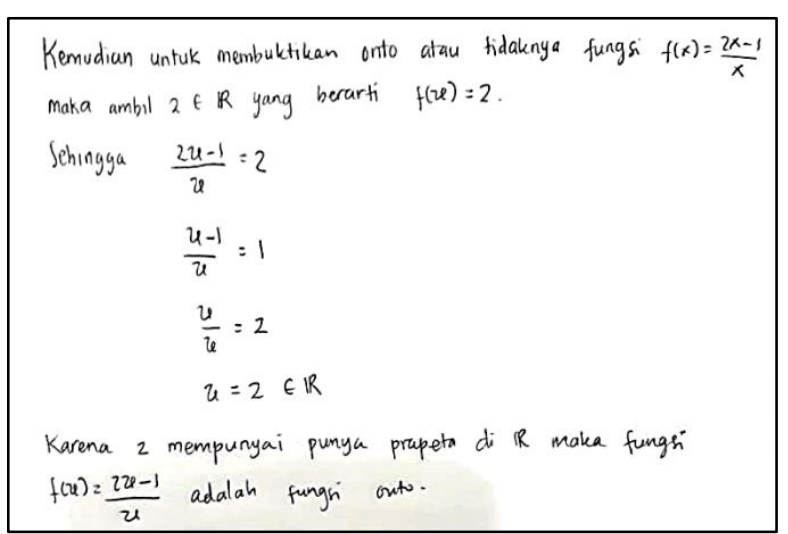

$$
\begin{aligned}
& \text { To proof whether the function is onto or not, } \\
& \text { choose } 2 \in R \text { that means } f(x)=2 \text {, so that } \\
& \frac{2 x-1}{x}=2 \\
& \frac{x-1}{x}=1 \\
& \frac{x}{x}=2 \\
& x=2 \in R \\
& \text { Because } 2 \text { has pre-map in } \mathrm{R} \text {, so function } f \\
& \text { is onto }
\end{aligned}
$$

Figure 1. Subject's answer who experience misconceptions of representation

Figure 1 show that the subject takes one fixed element of $R$, which is 2 to show that $2 \in R$ has an inverse image in $R-\{0\}$. And with this argument, subject concluded that $f(x)$ is an onto function. It is also said by Selden \& Selden (1987) that any wrong proof's strategies are usually using examples to represent the whole. And according to Stavrou (2014) students usually replaced formal proofs with specific examples. Subject's answer in Figure 1 also shows that there are another types of misconception, that is misconception symbol and it will be explained later.

\subsection{Misconception of Symbol}

In this type of misconception, subject experienced a misconception about understanding mathematical symbols. The subject ignored the important information contained in the symbol so that subject's concept about mathematical symbol is different with the existing concept. This is indicated by subject's inability to understand symbol $f: R-\{0\} \rightarrow R$. Figure 2 shows subject's answer which experienced misconception symbol.

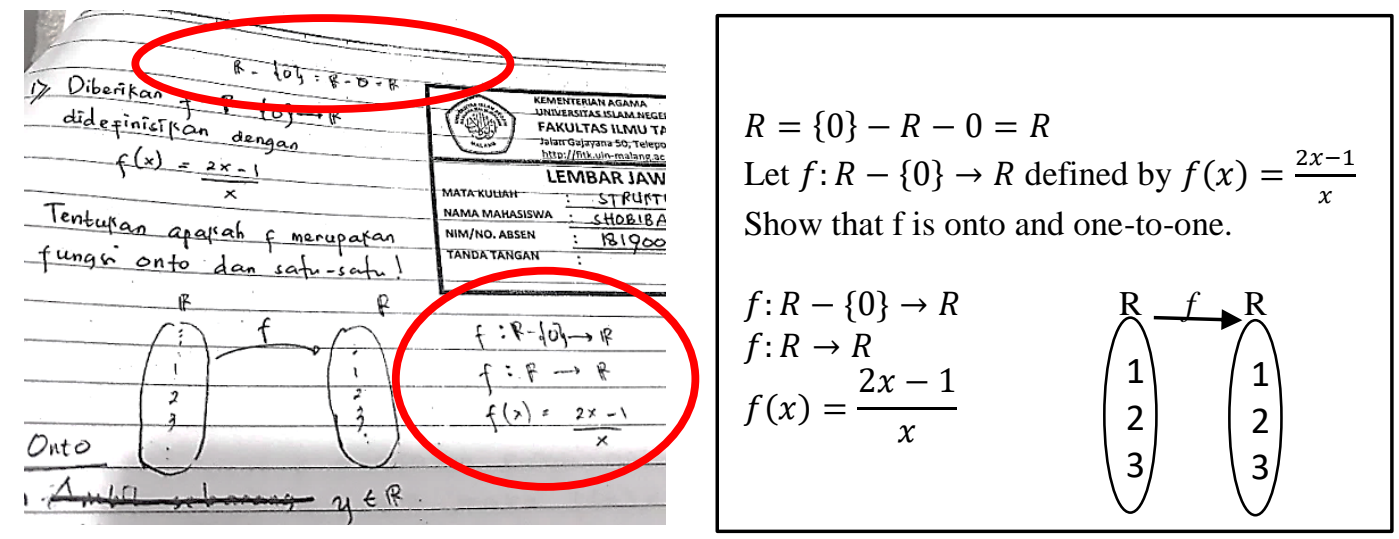

Figure 2. Subject's answer who experience misconception symbol

Figure 2 shows that subject cannot understand about the symbol of function or mapping. Subject expect that $R-\{0\}$ means $R$ subtract $\{0\}$, so that the result is R. Subject ignore about the operation of sets, that $R-\{0\}$ means that set of real number, except $\{0\}$. This wrong conception is not suitable with the conception that exist, it make subject misconception about the symbol and also cannot proof onto function. This kind of misconception is called with vocabulary misconceptions that addressed by focusing on the part of the language that is 
misunderstood (Holmes, Miedema, \& Haugen, 2013). In this case, subject has a vocabulary problem of defining or interpreting symbol of function.

\subsection{Misconception of Proof Strategies}

In this type of misconception the subject only rewrites the definition, the subject does not prove anything but has concluded that his statement is proven. Figure 3 shows subject's answer who experience misconception of proofs strategy.

$$
\begin{aligned}
& \text { (i) Ambil sebarang } a, b \in \mathbb{R} \text { maka } f(a)=\frac{2 a-1}{a} \text { dan } f(b)=\frac{2 b-1}{b} \\
& \text { misal } f(a)=f(b) \text { maka berlaku } \\
& \frac{2 a-1}{a}=\frac{2 b-1}{b} \text { sehingga } b=a \text {, karena untule sebarang } \\
& a, b \in R \text { dengan } f(a)=\frac{2 a-1}{a} \text { berlaku } b=a \\
& \text { maka } f(x)=\frac{2 x-1}{x} \text { adalah fungsi satursat. }
\end{aligned}
$$

Figure 3. Subject's answer who experience misconception of proofs strategy

Students' answer in Figure 3 shows that subject cannot understand or get misconception in proving strategy. Function $f: A \rightarrow B$ is called one-to-one (injective) if and only if different elements of A always have different images under $f$. To prove that a function is one-to-one is using its contrapositive that is for any $\mathrm{a}, \mathrm{b}$ in A $f(a)=f(b)$ always implies $a=b$. But subject in this type of misconception ignoring this proving strategy, they just expect to explain the definition and conclude that the function is one-to-one. This kind of misconception is also called with logical errors (Sari, Waluyo, Ainur, \& Darmaningsih, 2018), that is students' proof framework is incorrect and thir argument is invalid.

\section{CONCLUSION}

This research shows that there are three types of misconceptions that occured, including: (1) proving a general case just by specific examples (misconception of representation); (2) misconceptions about mathematical symbols (misconceptions of symbols); (3) proving by misusing proving strategy (misconception of the proofs strategy). It is necessary to improve students' proving skills and strategy, because understanding about definition is not enough to construct a valid proof. A lecturer should familiarize students with proving framework and exercise so they can writing proof in a correct way and framework. A further study can be conducted by investigating students' thinking or interviewing them to know about what they are thinking on every step.

\section{REFERENCES}

Boero, P., Fenaroli, G., \& Guala, E. (2018). Mathematical argumentation in elementary teacher education: The key role of the cultural analysis of the content. In A. J. Stylianides \& G. Harel (Eds.), Advances in mathematics education research on proof and proving (pp. 4967). Cham, Switzerland: Springer International Publishing.

Creswell, J.W. (2012). Educational research: Planning, conducting, and evaluating quantitative and qualitative research (4th Ed.). Boston, MA: Pearson. 
Dawkins, P. C., \& Weber, K. (2017). Values and norms of proof for mathematicians and students. Educational Studies in Mathematics, 95(2), 123-142.

Dulock, H. L. (1993). Research design: Descriptive research. Journal of Pediatric Oncology Nursing, 10(4), 154-157.

Gilbert, L., \& Gilbert, J. (2009). Elements of modern algebra. USA: Cengage Learning.

Griffin, P., McGaw, B., \& Care, E (2012). Assessment and teaching of 21st century skills. Dordrecht, Netherlands: Springer.

Hammer, D. (1996). Misconceptions or p-prims: How alternative perspectives of cognitive structure influence instructional perceptions and intentions. The Journal of the learning science 5, 97-127.

Hasan, S., Bagayoko, D., \& Kelley, E. L. (1999). Misconceptions and the certainty of response index (CRI). Physics education, 34(5), 294.

Holmes, V., Miedema, C., \& Haugen, N. (2013). Data-driven intervention: Correcting Mathematics Students' Misconceptions, Not Mistakes. Mathematics Educator, 23(1), 24 44.

Lesseig, K. (2016). Investigating mathematical knowledge for teaching proof in professional development. International Journal of Research in Education and Science, 2(2), 253-270.

Li, X. (2010). Cognitive analysis of students' errors and misconceptions in variables, equations, and functions (Doctoral dissertation). College Station, Texas: Texas A \& M University.

Mata-Pereira, J., \& da Ponte, J. P. (2017). Enhancing students' mathematical reasoning in the classroom: teacher actions facilitating generalization and justification. Educational Studies in Mathematics, 96(2), 169-186.

Moon, A., Stanford, C., Cole, R., \& Towns, M. (2017). Analysis of inquiry materials to explain complexity of chemical reasoning in physical chemistry students' argumentation. Journal of Research in Science Teaching, 54(10), 1322-1346.

Orton, A. (1983). Students understanding of integration. Educational studies in mathematics, 14(1), 1-18.

Radatz, H. (1979). Error analysis in mathematics education. Journal for Research in Mathematics Education, 10,163-172

Reid, D. (2005). The meaning of proof in mathematics education. In Proceedings of the 4th Conference of the European Society for Research in Mathematics Education (pp. 458468). San Feliu de Guxols, Spain: CERME.

Sari, C. K., Waluyo, M., Ainur, C. M., \& Darmaningsih, E. N. (2018). Logical errors on proving theorem. Journal of Physics: Conference Series, 948(1), 012059. https://doi.org/10.1088/1742-6596/948/1/012059

Selden, A., \& Selden, J. (1987). Errors and misconceptions in college level theorem proving. In Proceedings of the second international seminar on misconceptions and educational strategies in science and mathematics (Vol. 3, pp. 457-470). Ithaca, NY: Cornell University.

Stavrou, S. (2014). Common errors and misconceptions in mathematical proving by education undergraduates. Issues in the Undergraduate Mathematics Preparation of School Teachers, 1, 1-8. 